\title{
Clinical Differences in Patients with Alzheimer's Disease According to the Presence or Absence of Anosognosia: Implications for Perceived Quality of Life
}

\author{
Josep L. Conde-Sala ${ }^{\mathrm{a}, *}$, Ramón Reñé-Ramírez ${ }^{\mathrm{b}}$, Oriol Turró-Garriga ${ }^{\mathrm{c}, \mathrm{d}}$, Jordi Gascón-Bayarri ${ }^{\mathrm{b}}$, \\ Montserrat Juncadella-Puig ${ }^{\mathrm{b}}$, Laura Moreno-Cordón ${ }^{\mathrm{b}}$, Vanesa Viñas-Diez ${ }^{\mathrm{b}}$ and Josep Garre-Olmo ${ }^{\mathrm{c}, \mathrm{e}}$ \\ ${ }^{a}$ Faculty of Psychology, University of Barcelona, Barcelona, Spain \\ ${ }^{\mathrm{b}}$ Dementia Unit, Department of Neurology, Bellvitge University Hospital, Hospitalet de Llobregat, Spain \\ ${ }^{\mathrm{c}}$ Research Unit, Santa Caterina Hospital, Institut d'Assistència Sanitària, Salt, Spain \\ ${ }^{\mathrm{d}}$ Department of Psychiatry and Forensic Medicine, Autonomous University of Barcelona, Bellaterra, Spain \\ ${ }^{\mathrm{e}}$ Department of Psychology, University of Girona, Girona, Spain
}

Handling Associate Editor: Ramon Luengo-Fernandez

Accepted 2 October 2012

\begin{abstract}
This study aimed to determine the factors that predict anosognosia in patients with Alzheimer's disease (AD) and to examine the effect of anosognosia on patient and caregiver perceptions of the patient's quality of life (QoL-p), using a cross-sectional design with 164 patients and their caregivers. Instruments of measurement included Anosognosia QuestionnaireDementia, Geriatric Depression Scale, Quality of Life in AD (QoL-AD), Disability Assessment for Dementia, Neuropsychiatric Inventory, and the Global Deterioration Scale (GDS). A binary logistic regression analysis was performed to identify the factors that predict anosognosia, while a linear regression analysis was conducted to determine the factors associated with QoL-AD. The degree of anosognosia increased in line with GDS stage $(F(2,161)=41.3, p<0.001)$. In the binary regression analysis, the variables that predicted anosognosia were more neuropsychiatric symptoms ( $\mathrm{OR}=1.11,95 \% \mathrm{CI}: 1.06-1.17, p<0.001)$, deficits in $\mathrm{ADL}(\mathrm{OR}=0.88,95 \%$ CI: $0.83-0.94, p<0.001)$, less depression $(\mathrm{OR}=0.66,95 \%$ CI: $0.54-0.82, p<0.001)$, and older age $(\mathrm{OR}=1.08,95 \% \mathrm{CI}: 1.00-1.15, p=0.027)$. With regards to QoL-p, the multiple linear regression analysis for patients $\left(r^{2}=0.486\right)$ showed that less depression $(\beta=-0.52, p<0.001)$ and greater anosognosia $(\beta=0.40, p<0.001)$ explained $33 \%$ and $10 \%$ of the variance in QoL-AD, respectively. Greater anosognosia was associated with better perceived QoL-p, especially in advanced GDS stages. Anosognosia was associated with greater caregiver burden and a greater discrepancy between patient and caregiver ratings of QoL-p.
\end{abstract}

Keywords: Alzheimer's disease, anosognosia, awareness, caregivers, depression, neuropsychiatry, patients, quality of life

Supplementary data available online: http://www.j-alz.com/issues/33/vol33-4.html\#supplementarydata06

\footnotetext{
*Correspondence to: Josep Lluís Conde-Sala, University of Barcelona, Passeig Vall d'Hebron, 171, 08035 Barcelona, Spain. Tel.: +34 93312 5814; Fax: +34 93402 1368; E-mail: jllconde@ ub.edu.
}

\section{INTRODUCTION}

The concept of anosognosia refers to a lack of awareness regarding the difficulties or deficits associated with an illness, and it has long been recognized as an important feature of Alzheimer's disease (AD) [1]. 
Specifically, the person with AD may show a lack of awareness regarding impairments related to activities of daily living (ADL) [2] or their neuropsychological deficits, especially memory [3, 4]. Anosognosia can have important implications as patients underestimate their limitations in relation to quality of life [5-7] and are more prone to engage in dangerous behaviors [8]. It can also lead to increased caregiver burden [9].

Estimates of the prevalence of anosognosia in AD vary widely between $20 \%$ [10] and $80 \%$ [11] and illustrates the enormous complexity and heterogeneity of the condition [12-15]. A key contributor to this variability is the wide range of methods used to measure anosognosia, which include the use of questionnaires to compare patient and caregiver ratings [10], the clinical judgment of professionals in relation to an anosognosia scale [11], and the administration of neuropsychological tests [3].

One key question is whether anosognosia forms part of the general characteristics of the disease process or whether it is a specific syndrome that is more common in certain patients. Although the majority of studies consider that anosognosia increases in line with the severity of dementia [4, 15-20], this is not always the case [21-23]. A similar discrepancy has been observed in relation to scores on the Mini-Mental State Examination (MMSE), which some studies have found to be negatively correlated with anosognosia [3, 10, 18], while others have failed to confirm such a relationship [21, 22, 24].

With regards to the hypothesis of specificity in relation to anosognosia, various studies have associated it with specific neurological changes, such as an increased density of amyloid plaques in the prosubiculum [25], or with frontal lobe dysfunction and the related behavioral problems [21, 24, 26-29]. From this perspective, anosognosia would be a more common symptom of frontotemporal dementia than of $\mathrm{AD}$ [30].

These two domains of anosognosia, that is, related to cognitive deficits and to behavioral problems, were analyzed by Starkstein et al. [31], who considered that they might constitute two independent phenomena in the context of AD. Anosognosia of cognitive/functional deficits was found to be related to the severity of dementia, whereas an unawareness of behavior problems appeared to form part of a disinhibition syndrome.

The findings are more consistent in relation to the symptoms associated with the anosognosia. Patients with anosognosia present deficits in ADL [2-4, 10] and a greater number of behavioral and psychological symptoms of dementia (BPSD) [32] such as disinhibition [4, 18, 27], apathy [28, 33], irritability and anxiety [4, 10, 16], agitation [20, 28], and aberrant motor behavior [28].

A number of aspects merit particular mention. One is the relationship between depression and anosognosia. Although some authors have found a negative correlation between the two $[11,17,18,20]$, others have failed to confirm this [21, 22, 28, 34]. Migliorelli et al. [35] reported a negative correlation between dysthymia and anosognosia in the early stages of $\mathrm{AD}$, and suggested that this was an emotional reaction to the awareness of cognitive impairment.

A further aspect to consider is the relationship between anosognosia and patient and caregiver perceptions of the patient's quality of life (QoL-p). Some previous studies have reported an association between anosognosia and a better rating of QoL-p in patients with moderate dementia [7], but this was not the case for those with mild dementia [7,36]. The level of agreement between patient and caregiver ratings of QoL-p has also been shown to be influenced by anosognosia $[5,6,36]$.

In relation to these aspects, the present study seeks to clarify which factors are predictive of and associated with anosognosia, to examine the reasons for the discrepancies in the literature with regards to depression and anosognosia, and to determine the role played by anosognosia with respect to the discrepancies between patient and caregiver ratings of the QoL-p. Specifically, the aims were: 1) to identify the clinical and socio-demographic factors associated with the presence/absence of anosognosia and the factors that predict it; and 2) to examine how the presence of anosognosia affects patient and caregiver ratings of QoL-p.

\section{MATERIALS AND METHODS}

\section{Design and study population}

This observational, cross-sectional, and analytic study included a consecutive sample of out-patients seen at the Dementia Unit of the Department of Neurology at Bellvitge University Hospital (Hospitalet de Llobregat, Barcelona) and diagnosed as either AD according to DSM-IV (Diagnostic and Statistical Manual of Mental Disorders) criteria [37] or probable AD according to NINCDS-ADRDA (National Institute of Neurological and Communicative Disorders and Stroke/Alzheimer's Disease and Related Disorders 
Associations) criteria [38], and who had a score on the MMSE [39] of between 10 and 28, thereby enabling the QoL scale to be applied [40, 41]. The sample also comprised their respective caregivers, with the main caregiver being defined as the person who was continuously responsible for helping the patient with ADL. Patients were excluded if they presented vascular or traumatic events, alcohol or substance dependency or abuse, and if they had severe communication problems that prevented them from responding adequately to the assessment questions. The study was approved by the hospital's Clinical Research Ethics Committee.

\section{Instruments}

\section{Clinical and socio-demographic data}

Socio-demographic data for patients (age, gender, schooling, months since diagnosis) were gathered using an ad hoc structured questionnaire.

\section{Anosognosia}

The Anosognosia Questionnaire-Dementia (AQ-D) $[10,17]$ was administered to patients and caregivers. It comprises 30 items that refer to cognitive/functional deficits and personality changes, with each item being rated according to the frequency of occurrence, from 0 (never) to 3 (always). The total score therefore ranges from 0 to 90 , with higher scores indicating greater anosognosia. The final score is obtained by calculating the difference between caregiver and patient scores. In the original scale validation, its authors considered that severe anosognosia was present when this difference is $\geq 32$.

\section{Depression in the patient}

The Geriatric Depression Scale (GDS-d), in its 15item format [42], was administered directly to patients. The cut-off score for probable depression is 6 , while that for definite depression is 10 .

\section{Quality of life}

The Quality of Life-Alzheimer's Disease (QoL-AD) scale [40] is designed to assess QoL-p from both the patient's and the caregiver's perspective. It comprises 13 items that refer to different aspects of the patient's wellbeing. Scores for each item range from 1 (poor) to 4 (excellent), yielding a total score between 13 and 52 (the higher the score the better the QoL-p). The scale's authors considered that it was valid for patients with MMSE scores $>10$. In the present study both the patient and caregiver perspectives were assessed.

\section{Cognitive assessment of the patient}

This was based on the MMSE [39], a brief cognitive assessment tool whose score ranges from 0 to 30 (the lower the score the greater the cognitive deterioration). This is the most widely used screening tool for detecting cognitive impairment in $\mathrm{AD}$ and it shows close correspondence to the different stages of deterioration in the disease [43]. MMSE scores were corrected for age and education [44].

\section{Functional assessment of the patient}

The Disability Assessment for Dementia (DAD) [45], a measure of basic and instrumental ADL, was administered to caregivers. The DAD comprises 40 items and its total score ranges from 40 to 80 (the higher the score the greater functional capacity).

\section{Behavioral and psychological symptoms of dementia}

This aspect was evaluated by means of the Neuropsychiatric Inventory (NPI) [46], which comprises twelve subscales that assess the frequency and severity of twelve neuropsychiatric symptoms, based on information provided by caregivers. Scores range from 0 to 144 , and the higher the score the greater the frequency and severity of neuropsychiatric symptoms.

\section{Stage of dementia}

This was based on the criteria of the Global Deterioration Scale (GDS), a clinical assessment tool designed to determine the stage of a patient's dementia [47]. GDS 4 corresponds to cases of mild dementia, GDS 5 to moderate dementia, and GDS 6 to moderately severe dementia.

\section{Caregiver burden}

This was assessed using the Zarit Burden Interview (ZBI) [48], which comprises 22 items that are scored on a Likert scale ranging from 1 (never) to 5 (almost always). The total score therefore ranges between 22 and 110 (the higher the score the greater the burden).

\section{Procedure}

The neurologists from the Dementia Unit identified eligible patients according to the inclusion criteria and determined their stage of dementia on the GDS scale [47]. The sample was recruited between January and October 2011. Of the total number of patients who met the inclusion criteria, only four families declined to participate.

Prior to the initial assessment interview at Bellvitge University Hospital, the aims of the study were 
explained to patients and caregivers, and informed consent was obtained from all participants. Patients and their caregivers were then interviewed separately by two psychologists trained in the administration of the respective tests ands instruments.

\section{Statistical analysis}

A descriptive analysis was carried out of the clinical and socio-demographic characteristics of the sample, using absolute and relative frequencies for qualitative variables and measures of central trend and dispersion for quantitative variables.

Based on their score on the AQ-D patients were assigned to one of two groups, no or mild anosognosia (NM-AN) and severe anosognosia (S-AN), using the cut-off $(\geq 32)$ suggested by the scale's authors $[9,15]$. In order to optimize the utility and clinical interest of the results, patients without anosognosia ( $\leq 14$ AQ-D) and those with mild anosognosia (14-32 AQ-D) were grouped together, as the analysis of associated factors revealed no significant differences between these two subgroups.

Differences between the two groups (NM-AN and $\mathrm{S}-\mathrm{AN}$ ) in relation to qualitative clinical and sociodemographic variables were analyzed by means of the chi-squared test. Quantitative variables were analyzed by means of parametric or non-parametric tests, in accordance with criteria of normality. When there was a significant difference between two measures Cohen's $d$ was calculated in order to determine the effect size. The degree of bivariate association between AQ-D scores and the clinical factors of patients was determined by calculating global correlations in each of the two groups, according to criteria of normality ( $r_{\mathrm{S}}=$ Spearman, $r=$ Pearson $)$.

Predictive factors related to the dichotomous variable (NM-AN versus S-AN) were identified by means of a binary logistic regression analysis, using the Enter method (all variables in a single step) for global factors and the forward Wald method for disaggregated factors (NPI \& DAD).

The relevance of the factors associated with anosognosia was evaluated by multiple linear regression analysis, using AQ-D score as the dependent variable and considering both global data and data disaggregated by GDS stage. Finally, two multiple linear regression analyses were fitted to the sample data as a whole using QoL-AD scores as the dependent variable, the purpose being to identify the influence of the various factors on QoL, according to both patient and caregiver perceptions. This was done using the
Enter method (all variables in a single step) for global factors. In the multiple linear regression analysis, the coefficient of contribution for each variable was calculated by means of the solution suggested by Guilford and Fruchter [49]: beta coefficient $x$ the coefficient of correlation with the dependent variable.

For hypothesis contrasts, the level of statistical significance was set at 0.05. All data processing and analysis was performed using SPSS version 17.0 for Windows.

\section{RESULTS}

\section{Description of the sample}

The final study sample comprised 164 patients. Twenty five of the initial cases $(n=189)$ were excluded: in 14 cases only the family caregiver could be interviewed, in one case only the patient could be interviewed, and in ten cases the patient had an MMSE score below 10 .

The mean age of patients was $77.6 \pm 7.2$ years; 96 $(58.5 \%)$ of them were women and $98(59.7 \%)$ had received fewer than five years of schooling.

The mean MMSE score was $17.9 \pm 5.8$. With regards to the severity of dementia, 71 patients $(43.3 \%)$ met the criteria for GDS stage 4, 52 patients $(31.7 \%)$ the criteria for GDS stage 5 , and 41 patients $(25.0 \%)$

Table 1

Demographic and clinical data of patients

\begin{tabular}{|c|c|c|}
\hline & $n=164$ & \\
\hline Females $n(\%)$ & $96(58.5)$ & \\
\hline \multicolumn{3}{|l|}{ Schooling } \\
\hline$<5$ years $n(\%)$ & $98(59.8)$ & \\
\hline$\geq 5$ years $n(\%)$ & $66(40.2)$ & \\
\hline Age $($ mean $\pm S D)$ & $77.6 \pm 7.2$ & IQR (74.4-82.1) \\
\hline $\begin{array}{l}\text { Mini-Mental State } \\
\text { Examination }(\text { mean } \pm \text { SD) }\end{array}$ & $17.9 \pm 5.8$ & IQR (14.0-22.0) \\
\hline $\begin{array}{l}\text { Disability Assessment for } \\
\text { Dementia }(\text { mean } \pm \mathrm{SD})\end{array}$ & $56.5 \pm 10.4$ & IQR (48.0-66.0) \\
\hline $\begin{array}{l}\text { Neuropsychiatric Inventory } \\
\quad(\text { mean } \pm \text { SD })\end{array}$ & $27.5 \pm 21.2$ & IQR (12.0-36.0) \\
\hline $\begin{array}{l}\text { Geriatric Depression Scale } \\
\quad(\text { mean } \pm \mathrm{SD})\end{array}$ & $3.4 \pm 2.9$ & IQR (1.0-6.0) \\
\hline $\begin{array}{l}\text { Months since diagnosis } \\
\quad(\text { mean } \pm \mathrm{SD})\end{array}$ & $21.0 \pm 22.0$ & IQR (4.0-32.0) \\
\hline $\begin{array}{l}\text { Anosognosia } \\
\text { Questionnaire-Dementia } \\
(\text { mean } \pm \text { SD) }\end{array}$ & $36.3 \pm 18.9$ & IQR (21.0-52.0) \\
\hline \multicolumn{3}{|l|}{$\begin{array}{l}\text { QoL-AD of patient } \\
\quad(\text { mean } \pm \text { SD })\end{array}$} \\
\hline Patient & $35.1 \pm 4.7$ & IQR (23.0-31.0) \\
\hline Caregiver & $26.9 \pm 5.7$ & \\
\hline
\end{tabular}

IQR, interquartile range; QoL-AD, Quality of Life-Alzheimer's disease. 
Table 2

Related factors in patients with anosognosia

\begin{tabular}{|c|c|c|c|c|c|}
\hline & \multirow{2}{*}{$\begin{array}{c}\text { NM-AN } \\
n=69\end{array}$} & \multirow{2}{*}{$\begin{array}{l}\text { S-AN } \\
n=95\end{array}$} & \multicolumn{3}{|c|}{ Differences } \\
\hline & & & Test & $P$ & $d$ \\
\hline AQ-D. Total (mean \pm SD) & $18.2 \pm 10.2$ & $49.4 \pm 11.6$ & $17.8^{\mathrm{a}}$ & $<0.001$ & 2.85 \\
\hline Intellectual Functions & $16.3 \pm 9.4$ & $41.2 \pm 8.8$ & $17.1^{\mathrm{a}}$ & $<0.001$ & 2.73 \\
\hline Behavior & $1.7 \pm 3.1$ & $8.6 \pm 4.8$ & $8.3^{\mathrm{c}}$ & $<0.001$ & 1.70 \\
\hline Females $n(\%)$ & $40(58.0)$ & $56(58.9)$ & $0.0^{\mathrm{b}}$ & 1.000 & \\
\hline Schooling, $>5$ years $n(\%)$ & $26(37.7)$ & $40(42.1)$ & $0.1^{b}$ & 0.682 & \\
\hline Age $($ mean $\pm \mathrm{SD})$ & $76.0 \pm 7.1$ & $78.7 \pm 7.0$ & $2.8^{\mathrm{c}}$ & 0.005 & 0.38 \\
\hline $\operatorname{MMSE}($ mean \pm SD) & $19.5 \pm 5.4$ & $16.7 \pm 5.8$ & $2.6^{\mathrm{c}}$ & 0.009 & 0.50 \\
\hline DAD. Total (mean \pm SD) & $63.7 \pm 9.5$ & $51.3 \pm 7.5$ & $7.3^{\mathrm{c}}$ & $<0.001$ & 1.44 \\
\hline Basic ADL & $30.2 \pm 4.4$ & $24.9 \pm 4.6$ & $6.7^{\mathrm{c}}$ & $<0.001$ & 1.44 \\
\hline Instrumental ADL & $33.4 \pm 5.8$ & $26.3 \pm 3.7$ & $7.2^{\mathrm{c}}$ & $<0.001$ & 1.46 \\
\hline NPI. Total $($ mean \pm SD) & $13.8 \pm 9.1$ & $37.5 \pm 22.0$ & $7.7^{\mathrm{c}}$ & $<0.001$ & 1.40 \\
\hline Agitation & $1.2 \pm 2.4$ & $3.2 \pm 3.7$ & $4.1^{\mathrm{c}}$ & $<0.001$ & 0.63 \\
\hline Depression & $1.8 \pm 2.5$ & $2.7 \pm 3.4$ & $1.4^{\mathrm{c}}$ & 0.159 & \\
\hline Apathy & $3.2 \pm 3.7$ & $7.2 \pm 3.9$ & $5.8^{\mathrm{c}}$ & $<0.001$ & 1.05 \\
\hline Disinhibition & $0.2 \pm 0.5$ & $2.8 \pm 3.7$ & $5.4^{\mathrm{c}}$ & $<0.001$ & 0.98 \\
\hline Irritability & $1.7 \pm 2.9$ & $4.7 \pm 4.2$ & $5.0^{\mathrm{c}}$ & $<0.001$ & 0.83 \\
\hline Aberrant motor behavior & $0.6 \pm 1.5$ & $3.4 \pm 4.4$ & $4.2^{\mathrm{c}}$ & $<0.001$ & 0.85 \\
\hline Appetite disorders & $1.0 \pm 2.1$ & $3.6 \pm 3.9$ & $4.9^{\mathrm{c}}$ & $<0.001$ & 0.82 \\
\hline GDS-d $($ mean \pm SD) & $4.2 \pm 3.1$ & $2.9 \pm 2.6$ & $2.7^{\mathrm{c}}$ & 0.005 & 0.45 \\
\hline$\geq 6$ points $n(\%)$ & $25(36.2)$ & $19(20.2)$ & $4.4^{\mathrm{b}}$ & 0.036 & \\
\hline GDS, stage $5-6 n(\%)$ & $20(29.0)$ & $73(76.8)$ & $39.8^{\mathrm{b}}$ & $<0.001$ & \\
\hline Months since diagnosis (mean $\pm \mathrm{SD}$ ) & $12.5 \pm 13.0$ & $27.2 \pm 25.0$ & $4.6^{\mathrm{c}}$ & $<0.001$ & 0.73 \\
\hline \multicolumn{6}{|l|}{ QoL-AD of patients (mean \pm SD) } \\
\hline Patient & $34.0 \pm 5.0$ & $35.9 \pm 4.4$ & $2.4^{\mathrm{c}}$ & 0.014 & 0.40 \\
\hline Caregiver & $30.1 \pm 5.3$ & $24.6 \pm 4.7$ & $7.0^{\mathrm{a}}$ & $<0.001$ & 1.09 \\
\hline Diff. $(z, p ; d)$ & $5.3,<\mathbf{0 . 0 0 1} ; 0.75$ & $8.4,<\mathbf{0 . 0 0 1} ; 2.48$ & & & \\
\hline ZBI. Caregiver burden (mean \pm SD) & $43.3 \pm 12.8$ & $56.4 \pm 15.8$ & $5.1^{\mathrm{c}}$ & $<0.001$ & 0.91 \\
\hline
\end{tabular}

${ }^{\mathrm{a}} t$, Student's $t$ test $(\mathrm{df}=162) ;{ }^{\mathrm{b}} \chi^{2}$, Chi-squared test with Yates' correction $(\mathrm{df}=1) ;{ }^{\mathrm{c}} z$, Mann-Whitney $\mathrm{U} ; d$, Cohen's $d$. $p$-values $<0.05$ are shown in bold. NM-AN (No/Mild anosognosia) =<32; AQ-D, S-AN (Severe anosognosia) = $\geq 32$ AQ-D; AQ-D, Anosognosia Questionnaire-Dementia; MMSE, Mini-Mental State Examination; DAD, Disability Assessment for Dementia; ADL, Activities of daily living; NPI, Neuropsychiatric Inventory; GDS-d, Geriatric Depression Scale; GDS, Global Deterioration Scale; QoL-AD, Quality of Life-Alzheimer's disease; ZBI, Zarit Burden Interview.

the criteria for GDS stage 6. The mean AQ-D score was $36.3 \pm 18.9$, with 95 patients $(57.9 \%$; CI: 50.0-65.7) scoring $\geq 32$ on this scale. The clinical and sociodemographic data are shown in Table 1.

\section{Factors associated with anosognosia}

The associated factors were compared across the two groups: NM-AN $(n=69)$ and S-AN $(n=95)$. In the bivariate analysis, patients with $\mathrm{S}-\mathrm{AN}$ were older, scored lower on the MMSE, had more deficits in ADL, more symptoms on the NPI (agitation, apathy, disinhibition, irritability, aberrant motor behavior, and appetite disorders), a more advanced GDS stage, and had been diagnosed for longer. There were no significant differences related to gender or years of schooling (Table 2).

The correlations between AQ-D scores and ADL were significant in both groups, with the relationship being stronger for instrumental ADL (NM-AN, $\left.r_{\mathrm{S}}=-0.42, p<0.001 ; \mathrm{S}-\mathrm{AN}, r_{\mathrm{S}}=-0.40, p<0.001\right)$. The greatest differences between the two patient groups were observed in the correlations with the NPI. Whereas in the NM-AN group, there was only a weakly significant correlation with euphoria $\left(r_{\mathrm{s}}=0.24\right.$, $p=0.045$ ), the S-AN group showed significant correlations between the AQ-D and several neuropsychiatric symptoms: agitation $\left(r_{\mathrm{s}}=0.24, p=0.045\right)$, euphoria $\left(r_{\mathrm{s}}=0.29, p=0.003\right)$, disinhibition $\left(r_{\mathrm{s}}=0.34\right.$, $p=0.001)$, irritability $\left(r_{\mathrm{s}}=0.32, p=0.002\right)$, aberrant motor behavior $\left(r_{\mathrm{s}}=0.29, \quad p=0.003\right)$, and appetite/weight changes $\left(r_{\mathrm{s}}=0.29, p=0.004\right)$. Depression scores on the GDS-d were significantly and inversely correlated with the AQ-D when analyzing the total sample $\left(r_{\mathrm{s}}=-0.27, p<0.001\right)$. The complete correlational results can be consulted in the Supplementary Table 1 (available online: http://www.j-alz.com/ issues/33/vol33-4.html\#supplementarydata06).

The cognitive/functional subscale of the AQ-D showed a weakly significant correlation with MMSE scores $\left(r_{\mathrm{s}}=-0.28, p<0.001\right)$ and a strongly significant correlation with the DAD $\left(r_{\mathrm{s}}=-0.67, p<0.001\right)$. 
Table 3

Binary logistic regression analysis with/without severe anosognosia

\begin{tabular}{lrrrc}
\hline Method: Enter & B (SE) & OR & $95 \%$ CI & $p$ \\
\hline $\begin{array}{l}\text { Global factors } \\
\text { Behavior(NPI) }\end{array}$ & $0.11(0.02)$ & 1.11 & $1.06-1.17$ & $<\mathbf{0 . 0 0 1}$ \\
$\begin{array}{l}\text { Depression } \\
\text { (GDS-d) }\end{array}$ & $-0.40(0.10)$ & 0.66 & $0.54-0.82$ & $<\mathbf{0 . 0 0 1}$ \\
Function: ADL & $-0.11(0.03)$ & 0.88 & $0.83-0.94$ & $<\mathbf{0 . 0 0 1}$ \\
(DAD) & & & & \\
Age & $0.07(0.03)$ & 1.08 & $1.00-1.15$ & $\mathbf{0 . 0 2 7}$ \\
Cognition (MMSE) & $-0.04(0.04)$ & 0.95 & $0.87-1.04$ & 0.328 \\
& & & & \\
Method: Forward & B (SE) & OR & $95 \%$ CI & $p$ \\
$\quad$ Wald & & & & \\
Disaggregated factors & & & & \\
$\quad$ NPI \& DAD) & & & & \\
Instrumental ADL & $-0.34(0.06)$ & 0.70 & $0.62-0.80$ & $<\mathbf{0 . 0 0 1}$ \\
(DAD) & & & & \\
Depression & $-0.37(0.10)$ & 0.68 & $0.55-0.84$ & $<\mathbf{0 . 0 0 1}$ \\
(GDS-d) & & & & \\
Disinhibition (NPI) & $0.67(0.26)$ & 1.96 & $1.17-3.26$ & $\mathbf{0 . 0 1 0}$ \\
Irritability (NPI) & $0.20(0.07)$ & 1.22 & $1.05-1.43$ & $\mathbf{0 . 0 1 0}$ \\
Age & $0.06(0.03)$ & 1.07 & $0.99-1.14$ & 0.053 \\
\hline Binary dependent variab & & & & \\
\end{tabular}

Binary dependent variable: $1=<32$ AQ-D; $2=\geq 32$ AQ-D; $p$-values $<0.05$ are shown in bold; $B$, unstandardized coefficient; $S E$, standard Error; OR, odds ratio; CI, confidence interval; AQ-D, Anosognosia Questionnaire-Dementia; MMSE, Mini-Mental State Examination; DAD, Disability Assessment for Dementia; IADL, instrumental activities of daily living; NPI, Neuropsychiatric Inventory; GDS-d, Geriatric Depression Scale.

The behavioral subscale of the AQ-D showed a strong correlation with the NPI $\left(r_{\mathrm{s}}=0.63, p<0.001\right)$.

Regarding depression, patients in the NM-AN group scored higher when they were assessed directly with the GDS-d. By contrast, there were no significant differences when depression was rated by caregivers via the NPI. The correlation between the GDS-d and NPIdepression was weak, although it was positive for the sample as a whole $\left(r_{\mathrm{s}}=0.23, p=0.002\right)$.

\section{Factors predictive of anosognosia}

In the binary logistic regression model, the factors that predicted the presence of S-AN were a greater frequency and severity of BPSD (NPI), less depression (GDS-d), poorer functional ability (DAD), and older age. The MMSE score was not significant due to its high collinearity with the DAD, although the MMSE did become a significant predictor $(\mathrm{OR}=0.90,95 \%$ CI: $0.83-0.97, p=0.010$ ) when the DAD was removed from the regression analysis.

The regression analysis applied to the disaggregated factors of the NPI and DAD showed that deficits in instrumental ADL (DAD), less depression (GDS-d), NPI-irritability, and NPI-disinhibition were all significant (Table 3). Scores on the NPI subscales agitation, apathy, aberrant motor behavior, and appetite disorders were not predictive of anosognosia.

\section{Anosognosia and severity of dementia}

Scores on the AQ-D increased in line with the severity of dementia in both NM-AN and S-AN

Table 4

Anosognosia and GDS stage. Bivariate and multiple linear regression analyses

\begin{tabular}{|c|c|c|c|c|c|c|c|c|c|c|}
\hline & \multicolumn{2}{|c|}{ GDS 4} & \multicolumn{2}{|c|}{ GDS 5} & \multicolumn{2}{|c|}{ GDS 6} & \multicolumn{2}{|c|}{ Differences } & & \\
\hline & $n$ & $\overline{\text { Mean } \pm \mathrm{SD}}$ & $n$ & $\overline{\text { Mean } \pm \mathrm{SD}}$ & $n$ & $\overline{\text { Mean } \pm \mathrm{SD}}$ & $F(\mathrm{df})$ & $p$ & & \\
\hline \multicolumn{11}{|l|}{ A) AQ-D scores } \\
\hline All cases & 71 & $24.5 \pm 16.0^{\mathrm{a}}$ & 52 & $40.7 \pm 14.0^{\mathrm{b}}$ & 41 & $51.1 \pm 16.3^{\mathrm{c}}$ & $41.3(2,161)$ & $<0.001$ & & \\
\hline 1. NM-AN & 49 & $16.0 \pm 10.4^{\mathrm{a}}$ & 15 & $23.8 \pm 6.9$ & 5 & $23.4 \pm 8.7$ & $4.3(2,66)$ & 0.016 & & \\
\hline 2. S-AN & 22 & $43.4 \pm 8.3$ & 37 & $47.6 \pm 9.5^{b}$ & 36 & $55.0 \pm 13.0^{\mathrm{c}}$ & $8.7(2,92)$ & $<0.001$ & & \\
\hline Diff. $1 / 2(t, p ; d)$ & 10.7 & $<\mathbf{0 . 0 0 1} ; 2.9$ & 8.7 & $<\mathbf{0 . 0 0 1} ; 2.8$ & 5.2 & $<0.001 ; 2.8$ & & & & \\
\hline \multicolumn{11}{|l|}{$\begin{array}{l}\text { B) AQ-D Multiple linear } \\
\text { regression }\end{array}$} \\
\hline & \multicolumn{2}{|c|}{ GDS 4} & \multicolumn{2}{|c|}{ GDS 5} & \multicolumn{2}{|c|}{ GDS 6} & \multicolumn{2}{|c|}{ All cases } & & \\
\hline & $r^{2}=0.611$ & & $r^{2}=0.452$ & & $r^{2}=0.342$ & & $r^{2}=0.643$ & & & \\
\hline & $\beta$ & $p$ & $\beta$ & $p$ & $\beta$ & $p$ & $\beta$ & $p$ & $r$ & $\mathrm{CC}$ \\
\hline Behavior (NPI) & 0.30 & 0.002 & 0.47 & $<0.001$ & 0.52 & 0.001 & 0.37 & $<0.001$ & 0.61 & 23.4 \\
\hline Depression (GDS-d) & -0.39 & $<0.001$ & -0.27 & 0.015 & -0.16 & 0.278 & -0.24 & $<0.001$ & -0.27 & 6.7 \\
\hline Function (DAD) & -0.45 & $<0.001$ & -0.11 & 0.332 & -0.07 & 0.631 & -0.42 & $<0.001$ & -0.67 & 28.4 \\
\hline Months since diagnosis & -0.02 & 0.728 & 0.24 & 0.029 & 0.32 & 0.054 & 0.14 & 0.012 & 0.41 & 5.8 \\
\hline$F(\mathrm{df}), p$ & $25.5(4,65)$ & $<0.001$ & $9.6(4,47)$ & $<0.001$ & $4.6(4,36)$ & 0.004 & $71.1(4,159)$ & $<0.001$ & & \\
\hline
\end{tabular}

A) Bivariate analysis. GDS, Global Deterioration Scale; Groups: 1. NM-AN (No/Mild anosognosia) $=<32$ AQ-D, 2 . S-AN (Severe anosognosia) $=\geq 32$ AQ-D; $F$, ANOVA, significant with Bonferroni post-hoc: ${ }^{\mathrm{a} C}$ Contrast GDS $4-5$, ${ }^{\mathrm{b}}$ Contrast GDS 5-6, ${ }^{\mathrm{c}}$ Contrast GDS $4-6$; $t$, Student's $t$ test; $d$, Cohen's $d$. $p$-values $<0.05$ are shown in bold. B) Multiple linear regression. $F$, ANOVA; $r^{2}$, coefficient of determination; $\beta$, standardized beta coefficient: $r$, Pearson correlation (zero-order); CC, coefficient of contribution (\%), [( $\beta$. $r)$ x 100)]. AQ-D, Anosognosia QuestionnaireDementia; GDS-d, Geriatric Depression Scale; NPI, Neuropsychiatric Inventory; DAD, Disability Assessment for Dementia. 
Table 5

Patient and caregiver ratings of the QoL of patients. Bivariate and multiple linear regression

\begin{tabular}{|c|c|c|c|c|c|c|c|c|}
\hline & \multicolumn{2}{|c|}{ GDS 4} & \multicolumn{2}{|c|}{ GDS 5} & \multicolumn{2}{|c|}{ GDS 6} & \multicolumn{2}{|c|}{ Difference } \\
\hline & $n$ & Mean \pm SD & $n$ & Mean \pm SD & $n$ & Mean \pm SD & Test (df) & $p$ \\
\hline \multicolumn{9}{|l|}{ A) QoL-AD scores } \\
\hline \multicolumn{9}{|l|}{ Patients } \\
\hline All cases & 71 & $35.6(4.6)$ & 52 & $34.6(4.4)$ & 41 & $34.6(5.3)$ & $1.4^{*}(2)$ & 0.492 \\
\hline 1. NM-AN & 49 & $35.0(4.6)$ & 15 & $31.8(5.0)$ & 5 & $29.8(4.8)$ & $7.9 *(2)$ & 0.019 \\
\hline 2. S-AN & 22 & $37.0(4.4)$ & 37 & $35.7(3.6)$ & 36 & $35.3(5.1)$ & $1.5^{*}(2)$ & 0.466 \\
\hline Diff. $1 / 2(z, p ; d)$ & 1.5 & 0.118 & 2.4 & 0.014; 0.89 & 2.1 & $\mathbf{0 . 0 2 8} ; 1.11$ & & \\
\hline \multicolumn{9}{|l|}{ Caregivers } \\
\hline All cases & 71 & $29.8(5.7)^{\mathrm{a}}$ & 52 & $25.7(4.0)$ & 41 & $23.5(4.9)^{\mathrm{c}}$ & $22.0^{* *}(2,161)$ & $<0.001$ \\
\hline 1. NM-AN & 49 & $31.3(5.4)$ & 15 & $27.8(3.7)$ & 5 & $26.2(4.6)$ & $4.3^{* *}(2,66)$ & 0.016 \\
\hline 2. S-AN & 22 & $26.4(4.9)$ & 37 & $24.9(3.9)$ & 36 & $23.1(4.9)^{\mathrm{c}}$ & $3.7^{* *}(2,92)$ & 0.028 \\
\hline Diff. $1 / 2(t, p ; d)$ & 3.5 & $\mathbf{0 . 0 0 1} ; 0.95$ & 2.3 & $\mathbf{0 . 0 2 2} ; 0.76$ & 1.2 & 0.203 & & \\
\hline \multicolumn{9}{|l|}{ Diff. Patients-caregivers } \\
\hline NM-AN $(z, p ; d)$ & 4.3 & $<\mathbf{0 . 0 0 1} ; 0.73$ & 2.5 , & $\mathbf{0 . 0 1 0} ; 0.90$ & 2.0 & $\mathbf{0 . 0 4 3} ; 0.76$ & & \\
\hline \multirow[t]{5}{*}{$\mathrm{S}-\mathrm{AN}(z, p ; d)$} & 3.9 & $<\mathbf{0 . 0 0 1} ; 2.27$ & 5.3 & $<\mathbf{0 . 0 0 1} ; 2.87$ & 5.2 & $<\mathbf{0 . 0 0 1} ; 2.43$ & & \\
\hline & \multicolumn{8}{|c|}{ B. QoL-AD Multiple linear regression } \\
\hline & \multicolumn{4}{|c|}{ Patients (All cases) } & \multicolumn{4}{|c|}{ Caregivers (All cases) } \\
\hline & $r^{2}=0.486$ & & & & $r^{2}=0.510$ & & & \\
\hline & $\beta$ & $p$ & $r$ & $\mathrm{CC}$ & $\beta$ & $p$ & $r$ & $\mathrm{CC}$ \\
\hline Depression (GDS-d) & -0.52 & $<0.001$ & -0.63 & 33.1 & -0.20 & 0.001 & -0.13 & 2.8 \\
\hline Anosognosia (AQ-D) & 0.40 & $<0.001$ & 0.24 & 10.0 & -0.30 & 0.001 & -0.57 & 17.6 \\
\hline Function (DAD) & 0.23 & 0.008 & 0.12 & 2.9 & 0.37 & $<0.001$ & 0.62 & 23.3 \\
\hline Behavior (NPI) & -0.17 & 0.021 & -0.04 & 0.7 & -0.17 & 0.018 & -0.52 & 9.1 \\
\hline Cognition (MMSE) & 0.14 & 0.026 & 0.13 & 1.9 & -0.12 & 0.048 & 0.14 & -1.8 \\
\hline $\mathrm{F}(\mathrm{df}), p$ & $29.6(5,158)$, & $<0.001$ & & & $32.6(5,158)$, & $<0.001$ & & \\
\hline
\end{tabular}

A) Bivariate analysis. GDS, Global Deterioration Scale; Groups: 1. NM-AN (No/Mild anosognosia) =<32 AQ-D, 2. S-AN (Severe anosognosia $)=\geq 32 \mathrm{AQ}-\mathrm{D} ;{ }^{*} \chi^{2}$, Kruskal-Wallis, significant with Bonferroni post-hoc: no significant difference; ${ }^{* *} \mathrm{~F}$, ANOVA significant with Bonferroni post-hoc: ${ }^{\mathrm{a}}$ Contrast GDS $4-5,{ }^{\mathrm{b}}$ Contrast GDS 5-6, ${ }^{\mathrm{c}}$ Contrast GDS 4-6; $z$, Mann-Whitney U; $t$, Student's $t$ test; $d$, Cohen's $d$. $p$-values $<0.05$ are shown in bold. B) Multiple regression. F, ANOVA; $r^{2}$, coefficient of determination; $\beta$, standardized beta coefficient; $r$, Pearson correlation (zero-order); CC, coefficient of contribution (\%), [( $\beta . r) \times 100)]$. QoL-AD, Quality of Life-Alzheimer's disease; GDS-d, Geriatric Depression Scale; AQ-D, Anosognosia Questionnaire-Dementia; DAD, Disability Assessment for Dementia; NPI, Neuropsychiatric Inventory; MMSE, Mini-Mental State Examination.

patients. Similarly, the percentage of patients with $\mathrm{S}$-AN increased as the dementia became more severe (GDS $4=30.9 \%$; GDS $5=71.1 \%$; GDS $6=87.8 \%$ ) (Table 4A).

In the bivariate analysis of GDS stages, the differences between the NM-AN and S-AN groups with respect to apathy, aberrant motor behavior, and appetite disorders were only significant in the early stages of the disease. The only factors that remained significant across all the stages were disinhibition, irritability, and agitation (Supplementary Table 2).

In the linear regression analysis conducted according to GDS stage, the greatest number of relevant factors associated with the presence of S-AN was observed in relation to GDS stage 4 (deficits in ADL, neuropsychiatric symptoms, and less depression). As the severity of dementia increased, these factors became less relevant, such that the only factor that showed a significant association across all GDS stages was neuropsychiatric symptoms (NPI) (Table 4B).
The patient's quality of life and anosognosia

Patients

In the bivariate analysis, perceived QoL-p differed significantly between patients with S-AN and those with NM-AN, with the former giving higher ratings on the QoL-AD scale (Table 2). In the analysis by GDS stage, there were no significant differences in scores on the QoL-AD when considering the sample as a whole. However, when the two groups were analyzed separately, the score on the QoL-AD decreased significantly among NM-AN patients as their dementia became more severe, while there were no differences in S-AN patients. Scores on the QoL-AD were always lower among NM-AN patients than among those in the $\mathrm{S}$-AN group, and this difference became more marked with increasing severity of dementia, reaching significance at GDS stages 5 and 6 (Table 5A).

In the linear regression analysis, higher scores for perceived QoL-p were associated with less depres- 
sion, greater anosognosia, better ability in relation to instrumental ADL, and fewer neuropsychiatric symptoms. Depression and anosognosia were the main explanatory variables, accounting respectively for $33.1 \%$ and $10.0 \%$ of the variance in QoL-AD scores (Table 5B).

\section{Caregivers}

In the bivariate analysis, caregiver ratings of QoL$\mathrm{p}$ were higher for NM-AN patients than for those in the S-AN group (Table 2). In the analysis by GDS stage, ratings of QoL-p became worse as the severity of dementia increased, this being the case for both groups (NM-AN and S-AN), although the difference between the two was only significant at GDS stages 4 and 5 (Table 5A). Caregiver burden (ZBI) only showed significant correlations at these two stages, specifically with ratings of QoL-p (GDS $4, r_{\mathrm{s}}=-0.59$, $p<0.001$; GDS 5, $\left.r_{\mathrm{S}}=-0.38, p=0.005\right)$ and scores on the AQ-D (GDS 4, $r_{\mathrm{s}}=0.44, p<0.001$; GDS 5, $\left.r_{\mathrm{S}}=0.29, p=0.033\right)$.

In the linear regression analysis, higher ratings of QoL-p were associated with better functional ability, less anosognosia, less depression, and fewer neuropsychiatric symptoms. Anosognosia and functional ability explained, respectively, $17.6 \%$ and $23.3 \%$ of the variance in QoL-AD scores (Table 5B).

\section{Differences between patients and caregivers}

The bivariate analysis showed that for both groups of patients (Table 2) and all GDS stages (Table 5A), caregiver ratings were always worse than those of patients. A linear regression analysis with the difference in QoLAD scores (patients - caregivers) as the dependent variable $\left(r^{2}=0.468\right)$ revealed that anosognosia was the main variable ( $\beta=0.54, p<0.001, r=0.64$ ) associated with differences in patient and caregiver ratings of QoL, it accounting for $34.6 \%$ of the variance.

\section{DISCUSSION}

\section{Factors predictive of anosognosia}

The first objective of this study was to identify factors that predict anosognosia. The analysis showed that the most relevant variables in this regard were more symptoms on the NPI, less depression (GDS-d), and greater deficits in ADL. In line with previous research, the most important neuropsychiatric symptoms were found to be greater disinhibition $[4,18,27]$ and irritability $[4,10,16]$. The significant association between deficits in ADL and anosognosia has also been reported previously $[2-4,10]$. Overall, apathy was not a predictor of anosognosia, consistent with a specific study on this aspect [33]. In line with other previous findings $[28,50]$, apathy was correlated with anosognosia in our patients with mild dementia. However, this correlation was not maintained among patients with moderate or severe dementia. These results suggest that apathy is a disorder that increases in line with the severity of dementia regardless of the presence of anosognosia, and it may be considered a predictor of functional deterioration, especially regarding basic ADL [51].

\section{Anosognosia and severity of dementia: Associated and specific factors}

Scores on the AQ-D increased in line with the severity of dementia (GDS) in both NM-AN and S-AN patients, although more notably in the former. These results are consistent with previous findings regarding the relationship between the degree of anosognosia and severity of dementia [4, 16-20]. Some authors have, however, questioned these findings due to the lack of a significant correlation with the MMSE [21-24] or because they consider that the most significant aspect is frontal lobe dysfunction $[21,24]$ or behavioral problems [23], rather than the severity of dementia. In the present study, the MMSE also appeared as a predictive variable in the binary logistic regression analysis when the DAD variable was removed, with a high degree of collinearity between the two.

A further aspect is the difficulty of differentiating among disorders associated with anosognosia or with the severity of dementia. Although anosognosia does increase in line with the severity of dementia, this is also the case of other problems such as apathy, appetite disorders, and aberrant motor behavior. Differences between the NM-AN and S-AN groups with regard to these disorders were only present at the early stage of dementia, the distinction being lost in more advanced patients. This suggests that these disorders are more related to the stage of dementia than to anosognosia, and at all events they would only be associated with anosognosia in early-stage patients. This conclusion is supported by the results of a previous study that found a positive correlation between anosognosia and apathy, agitation, and aberrant motor behavior in patients with mild AD [28].

Disinhibition, irritability, and agitation seem to be more specifically associated with anosognosia as they were more common among patients in the S-AN group, including at advanced stages. Similarly, 
in the linear regression analysis, the only variable that remained significant across all stages was neuropsychiatric symptoms (NPI). These data suggest that greater anosognosia is associated with greater severity of dementia, although this relationship is more notable in patients with more BPSD, who probably present more frontal lobe dysfunctions [21, 24].

\section{Depression and anosognosia}

All the analyses of the present study reveal an inverse correlation between depression (assessed by the GDSd) and anosognosia, a finding consistent with a number of previous studies [11, 17, 18, 20, 35]. However, not all authors have found this relationship [21, 22, 28, 34]. This discrepancy may be due to a methodological problem. Whereas the former set of authors applied instruments directly to the patient, the latter assessed depression according to DSM-IV criteria for major depression [21, 34], using either the items from the AQ-D [22] or the NPI-Depression subscale [28].

Assessing depression in the patient directly during the early stages of dementia enables reliable information to be obtained, whereas it is possible than in more advanced stages, the patient's mood will also be affected by anosognosia. Our data support the hypothesis of those authors who found a negative correlation between anosognosia and depression, namely that a greater awareness of deficits (less anosognosia) is related to a reactive depressive mood, especially in the early stages of dementia.

\section{The patient's quality of life and anosognosia}

The second objective of this study was to examine the relationship between anosognosia and patient and caregiver ratings of the QoL-p. In line with previous research [7, 36], we found that in cases of mild AD (GDS stage 4), anosognosia did not produce differences in the perception of patients. Overall, patients with S-AN gave higher ratings of QoL, whereas those in the NM-AN group rated QoL as worse. This shows that a greater awareness of deficits and difficulties (less anosognosia) is related to a poorer perception of QoL, and highlights the relevance of psychological factors in the early stages of the disease (lower QoL-AD scores associated with greater depression and less anosognosia). Conversely, in more advanced stages biological factors would acquire greater importance (higher QoL$\mathrm{AD}$ scores associated with more anosognosia).

Caregiver ratings of QoL-p were lower as the severity of dementia increased, although the greatest differences related to anosognosia were observed in the early stages of the disease. These results could be related to the fact that caregiver burden [9] is more strongly correlated with QoL-p and AQ-D scores in the early stages, due to the greater initial impact of the disease.

Anosognosia was the most important variable in terms of explaining the differences between patient and caregiver ratings of QoL-p. Greater anosognosia was related to better perceived QoL-p among patients and to poorer ratings by caregivers. These data call into question the perception of QoL-p reported by patients with $\mathrm{S}-\mathrm{AN}$, especially in the advanced stages of dementia. This is consistent with the findings of various authors who consider that in patients with anosognosia the ratings of QoL-p are better [7, 36], less reliable, and should be interpreted with caution $[5,6]$.

In terms of objective criteria of impairment, caregiver ratings would seem to offer a better reflection of reality. Subjectively, however, the differing perceptions of patients and caregivers may represent two potentially valid perspectives $[6,12]$, although further research would be required to confirm this hypothesis.

\section{CONCLUSIONS}

This study makes two main contributions. Firstly, it identifies the functional deficits (neuropsychiatric symptoms) that are associated with greater anosognosia, highlighting instrumental ADL, disinhibition, and irritability as predictive factors. Less depression, assessed directly in the patients, was also a relevant predictor of anosognosia. Secondly, the study demonstrates that anosognosia is the most important factor in relation to the discrepancies between patient and caregiver ratings of the QoL-p. Patients with greater anosognosia rate their QoL as higher, this being particularly so in the advanced stages of dementia. Among caregivers, by contrast, greater anosognosia is associated with poorer ratings of the QoL-p, especially in the early stages of the disease, where it is strongly correlated with caregiver burden.

\section{Clinical implications}

Patients without anosognosia present more depression, while less depression is shown to be the most important factor in terms of better perceived QoL-p. Consequently, depression should be regarded as a key factor in the treatment of patients with AD. 
Behavioral symptoms are an important factor in patients with anosognosia. This is a more complicated issue as such symptoms form an intrinsic part of the disease, this being more notable among patients with anosognosia. A reduction in neuropsychiatric symptoms would lead to increased wellbeing in the patient and, especially, in family caregivers.

Patients' own ratings of their QoL should be accompanied by measures of depression and anosognosia. Whereas depression could lead to a more negative perception the presence of anosognosia could lead to overly positive ratings of QoL by the patient, hence the need for complementary measures.

Among caregivers, interventions that enable them to develop a better understanding of the nature of dementia, to maintain significant relationships with the patient [12], and which provide ongoing educational and emotional support to reduce burden could help them to have a more positive view of QoL-p [52, 53].

\section{Limitations and future directions}

The present research opted for a global study of anosognosia so as to analyze the clinical factors associated with it and to examine its effect on patient and caregiver ratings of the QoL-p. The study of how anosognosia affects the different neuropsychological domains (memory, language, executive functions, etc.) would require both a more homogeneous sample in relation to MMSE scores, as well as the use of specific tests to assess these domains. These aspects need to be addressed in future research. The controversial issue of depression and anosognosia could be analyzed in future studies in relation to the specific criteria of depression in AD [54].

Another key limitation of the present study is that it lacks a longitudinal perspective which would provide greater clarity regarding the factors associated with both anosognosia and QoL-p as dementia becomes more severe. Finally, it is acknowledged that the study did not consider, in detail, the potential influence of caregiver factors such as gender, burden, and mental health on the appraisal of anosognosia and QoL-p. Future studies should therefore analyze caregiver factors in relation to the latter two aspects.

\section{ACKNOWLEDGMENTS}

The authors are grateful for the support given to this study by the town council of Hospitalet de Llobregat. They would also like to thank the psychiatrist, Dr Joan Vilalta-Franch, for his help with methodological and statistical aspects of the research. This study was conducted within the framework of the project Assessing perceptions of patient quality of life in patients with Alzheimer's disease and their family caregivers over a two-year period, funded by Spain's Ministry of Science and Innovation (reference PSI2010-19014).

Authors' disclosures available online (http://www.jalz.com/disclosures/view.php?id=1539).

\section{REFERENCES}

[1] Reisberg B, Gordon B, McCarthy M, Ferris SH, deLeon MJ (1985) Insight and denial accompanying progressive cognitive decline in normal aging and Alzheimer's disease. In Geriatric Psychiatry: Ethical and Legal Issues, Stanley B, ed. American Psychiatric Press, Washington DC, pp. 19-39.

[2] Orfei MD, Varsi AE, Blundo C, Celia E, Casini AR, Caltagirone C, Spalletta G (2010) Anosognosia in mild cognitive impairment and mild Alzheimer's disease: Frequency and neuropsychological correlates. Am J Geriatr Psychiatry 18, 1133-1140.

[3] Leicht H, Berwig M, Gertz HJ (2010) Anosognosia in Alzheimer's disease: The role of impairment levels in assessment of insight across domains. J Int Neuropsychol Soc 16, 463-473.

[4] Starkstein SE, Jorge R, Mizrahi R, Robinson RG (2006) A diagnostic formulation for anosognosia in Alzheimer's disease. J Neurol Neurosurg Psychiatry 77, 719-725.

[5] Berwig M, Leicht H, Gertz HJ (2009) Critical evaluation of self-rated quality of life in mild cognitive impairment and Alzheimer's disease-further evidence for the impact of anosognosia and global cognitive impairment. J Nutr Health Aging 13, 226-230.

[6] Ready RE, Ott BR, Grace J (2006) Insight and cognitive impairment: Effects on quality-of-life reports from mild cognitive impairment and Alzheimer's disease patients. Am J Alzheimers Dis Other Demen 21, 242-248.

[7] Hurt CS, Banerjee S, Tunnard C, Whitehead DL, Tsolaki M, Mecocci P, Kloszewska I, Soininen H, Vellas B, Lovestone S (2010) Insight, cognition and quality of life in Alzheimer's disease. J Neurol Neurosurg Psychiatry 81, 331-336.

[8] Starkstein SE, Jorge R, Mizrahi R, Adrian J, Robinson RG (2007) Insight and danger in Alzheimer's disease. Eur J Neurol 14, 455-460.

[9] Turró-Garriga O, Garre-Olmo J, Vilalta-Franch J, Conde-Sala J, de Gracia-Blanco M, López-Pousa S (2012) Burden associated with the presence of anosognosia in Alzheimer's disease. Int J Geriatr Psychiatry, in Press. doi: 10.1002/gps.3824

[10] Migliorelli R, Tesón A, Sabe L, Petracca G, Petracchi M, Leiguarda R, Starkstein SE (1995) Anosognosia in Alzheimer's disease: A study of associated factors. J Neuropsychiatry Clin Neurosci 7, 338-344.

[11] Sevush S, Leve N (1993) Denial of memory deficit in Alzheimer's disease. Am J Psychiatry 150, 748-751.

[12] Smyth KA, Neundorfer MM, Koss E, Geldmacher DS, Ogrocki PK, Whitehouse PJ (2002) Quality of life and deficit identification in dementia. Dementia 1, 345358.

[13] Agnew SK, Morris RG (1998) The heterogeneity of anosognosia for memory impairment in Alzheimer's disease: A review of the literature and a proposed model. Aging Ment Health 2, 7-19. 
[14] Hannesdottir K, Morris RG (2007) Primary and secondary anosognosia for memory impairment in patients with Alzheimer's disease. Cortex 43, 1020-1030.

[15] Marková IS, Clare L, Wang M, Romero B, Kenny G (2005) Awareness in dementia: Conceptual issues. Aging Ment Health 9, 386-393.

[16] Vasterling JJ, Seltzer B, Foss JW, Vanderbrook V (1995) Unawareness of deficit in Alzheimer's disease: Domainspecific differences and disease correlates. Neuropsychiatry Neuropsychol Behav Neurol 8, 26-32.

[17] Starkstein SE, Chemerinski E, Sabe L, Kuzis G, Petracca G, Tesón A, Leiguarda R (1997) Prospective longitudinal study of depression and anosognosia in Alzheimer's disease. $\mathrm{Br} \mathrm{J}$ Psychiatry 171, 47-52.

[18] Kashiwa Y, Kitabayashi Y, Narumoto J, Nakamura K, Ueda H, Fukui K (2005) Anosognosia in Alzheimer's disease: Association with patient characteristics, psychiatric symptoms and cognitive deficits. Psychiatry Clin Neurosci 59, 697-704.

[19] Turró-Garriga O, Lopez-Pousa S, Vilalta-Franch J, GarreOlmo J (2012) Evaluation of anosognosia in Alzheimer's disease. Rev Neurol 54, 193-198.

[20] Harwood DG, Sultzer DL, Wheatley MV (2000) Impaired insight in Alzheimer disease: Association with cognitive deficits, psychiatric symptoms, and behavioral disturbances. Neuropsychiatry Neuropsychol Behav Neurol 13, 83-88.

[21] Reed BR, Jagust WJ, Coulter L (1993) Anosognosia in Alzheimer's disease: Relationships to depression, cognitive function, and cerebral perfusion. J Clin Exp Neuropsychol 15, 231-244.

[22] Almeida OP, Crocco EI (2000) Perception of cognitive deficits and behavior disorders in patients with Alzheimer's disease. Arq Neuropsiquiatr 58, 292-299.

[23] Weinstein EA, Friedland RP, Wagner EE (1994) Denial/unawareness of impairment and symbolic behavior in Alzheimer's disease. Neuropsychiatry Neuropsychology Behav Neurol 7, 176-184.

[24] Michon A, Deweer B, Pillon B, Agid Y, Dubois B (1994) Relation of anosognosia to frontal lobe dysfunction in Alzheimer's disease. J Neurol Neurosurg Psychiatry 57, 805-809.

[25] Marshall GA, Kaufer DI, Lopez OL, Rao GR, Hamilton RL, DeKosky ST (2004) Right prosubiculum amyloid plaque density correlates with anosognosia in Alzheimer's disease. J Neurol Neurosurg Psychiatry 75, 1396-1400.

[26] Sedaghat F, Dedousi E, Baloyannis I, Tegos T, Costa V, Dimitriadis AS, Baloyannis SJ (2010) Brain SPECT findings of anosognosia in Alzheimer's disease. J Alzheimers Dis 21, 641-647.

[27] Amanzio M, Torta DM, Sacco K, Cauda F, D'Agata F, Duca S, Leotta D, Palermo S, Geminiani GC (2011) Unawareness of deficits in Alzheimer's disease: Role of the cingulate cortex. Brain 134, 1061-1076.

[28] Spalletta G, Girardi P, Caltagirone C, Orfei MD (2012) Anosognosia and neuropsychiatric symptoms and disorders in mild Alzheimer disease and mild cognitive impairment. J Alzheimers Dis 29, 761-772.

[29] Salmon E, Perani D, Herholz K, Marique P, Kalbe E, Holthoff V, Delbeuck X, Beuthien-Baumann B, Pelati O, Lespagnard S, Collette F, Garraux G (2006) Neural correlates of anosognosia for cognitive impairment in Alzheimer's disease. Hum Brain Mapp 27, 588-597.

[30] Miller BL, Ikonte C, Ponton M, Levy M, Boone K, Darby A, Berman N, Mena I, Cummings JL (1997) A study of the LundManchester research criteria for frontotemporal dementia: Clinical and single-photon emission CT correlations. Neurology 48, 937-942.
[31] Starkstein SE, Sabe L, Chemerinski E, Jason L, Leiguarda R (1996) Two domains of anosognosia in Alzheimer's disease. J Neurol Neurosurg Psychiatry 61, 485-490.

[32] Vogel A, Waldorff FB, Waldemar G (2010) Impaired awareness of deficits and neuropsychiatric symptoms in early Alzheimer's disease: The Danish Alzheimer Intervention Study (DAISY). J Neuropsychiatry Clin Neurosci 22, 93-99.

[33] Starkstein SE, Brockman S, Bruce D, Petracca G (2010) Anosognosia is a significant predictor of apathy in Alzheimer's disease. J Neuropsychiatry Clin Neurosci 22, 378-383.

[34] Lopez OL, Becker JT, Somsak D, Dew MA, DeKosky ST (1994) Awareness of cognitive deficits and anosognosia in probable Alzheimer's disease. Eur Neurol 34, 277-282.

[35] Migliorelli R, Teson A, Sabe L, Petracchi M, Leiguarda R, Starkstein SE (1995) Prevalence and correlates of dysthymia and major depression among patients with Alzheimer's disease. Am J Psychiatry 152, 37-44.

[36] Vogel A, Mortensen EL, Hasselbalch SG, Andersen BB, Waldemar G (2006) Patient versus informant reported quality of life in the earliest phases of Alzheimer's disease. Int J Geriatr Psychiatry 21, 1132-1138.

[37] American Psychiatric Association (2001) Manual diagnóstico y estadístico de los trastornos mentales. 4 ed., texto revisado (DSM-IV-TR), Masson, Barcelona.

[38] McKhann G, Drachman D, Folstein M, Katzman R, Price D, Stadlan EM (1984) Clinical diagnosis of Alzheimer's disease: Report of the NINCDS-ADRDA Work Group under the auspices of Department of Health and Human Services task force on Alzheimer's disease. Neurology 34, 939-944.

[39] Folstein MF, Folstein SE, McHugh PR (1975) Mini Mental State. A practical method for grading the cognitive state of patients for the clinician. J Psychiatr Res 12, 189-198.

[40] Logsdon RG, Gibbons LE, McCurry SM, Teri L (2002) Assessing quality of life in older adults with cognitive impairment. Psychosom Med 64, 510-519.

[41] Karttunen K, Karppi P, Hiltunen A, Vanhanen M, Välimäki T, Martikainen J, Valtonen H, Sivenius J, Soininen H, Hartikainen S, Suhonen J, Pirttilä T; ALSOVA study group (2011) Neuropsychiatric symptoms and quality of life in patients with very mild and mild Alzheimer's disease. Int J Geriatr Psychiatry 26, 473-482.

[42] Sheikh JL, Yesavage JA (1986) Geriatric Depression Scale (GDS): Recent evidence and development of a shorter version. Clin Gerontol 5, 165-173.

[43] Kraemer HC, Taylor JL, Tinklenberg JR, Yesavage JA (1998) The stages of Alzheimer's disease: A reappraisal. Dement Geriatr Cogn Disord 9, 299-308.

[44] Blesa R, Pujol M, Aguilar M, Santacruz P, Bertran-Serra I, Hernández G, Sol JM, Peña-Casanova J; NORMACODEM Group. NORMAlisation of Cognitive, Functional Instruments for, DEMentia (2001) Clinical validity of the "mini-mental state' For Spanish speaking communities. Neuropsychologia 39, 1150-1157.

[45] Gélinas I, Gauthier L, McIntyre M, Gauthier S (1999) Development of a functional measure for persons with Alzheimer's disease: The Disability Assessment for Dementia. Am J Occup Ther 53, 471-481.

[46] Cummings JL, Mega M, Gray K, Rosemberg-Thompson S, Carusi DA, Gornbein J (1994) The neuropsychiatric inventory Comprehensive assessment of psychopathology in dementia. Neurology 44, 2308-2314.

[47] Reisberg B, Ferris SH, De Leon MJ, Crook T (1982) The Global Deterioration Scale for assessment of primary degenerative dementia. Am J Psychiatry 139, 1136-1139. 
[48] Zarit SH, Todd PA, Zarit JM (1986) Subjective burden of husbands and wives as caregiver: A longitudinal study. Gerontologist 26, 260-266.

[49] Guilford JP, Fruchter B (1973) Fundamental statistics in psychology and education (5th ed.). McGraw- Hill, New York.

[50] Derouesne C, Thibault S, Lagha-Pierucci S, Baudouin-Madec V, Ancri D, Lacomblez L (1999) Decreased awareness of cognitive deficits in patients with mild dementia of the Alzheimer type. Int J Geriat Psychiatry 14, 10191030.

[51] Boyle PA, Malloy PF, Salloway S, Cahn-Weiner DA, Cohen R, Cummings JL (2003) Executive dysfunction and apathy predict functional impairment in Alzheimer disease. Am J Geriatr Psychiatry 11, 214-221.
[52] Conde-Sala JL, Garre-Olmo J, Turró-Garriga O, López-Pousa S, Vilalta-Franch J (2009) Factors related to perceived quality of life in patients with Alzheimer's disease: The patient's perception compared with that of caregivers. Int J Geriatr Psychiatry 24, 585-594.

[53] Conde-Sala JL, Garre-Olmo J, Turró-Garriga O, VilaltaFranch J, López-Pousa S (2010) Quality of life of patients with Alzheimer's disease: Differential perceptions between spouse and adult child caregivers. Dement Geriatr Cogn Disord 29, 97-108.

[54] Olin JT, Katz IR, Meyers BS, Schneider LS, Lebowitz BDf (2002) Provisional diagnostic criteria for depression of Alzheimer disease: Rationale and background. Am J Geriatr Psychiatry 10, 129-141. 